\title{
ЗНАЧЕНИЕ ПЕРЕОТЛОЖЕННОЙ ПЫЛЬЦЫ МЕЖЛЕДНИКОВЫХ ТЕРМОФИЛЬНЫХ ДРЕВЕСНЫХ ПОРОД В СТРАТИГРАФИИ
}

С внедрением сепарационного метода обогащения пыльцы и спор значительно расширились возможности палинологических исследований. Для изучения стали доступными палиноморфы не только из органогенных, но и из минерогенных отложений различного генезиса. Однако в связи с этим возникли и трудности в интерпретации палинологических данных. Минерогенные отложения, особенно ледниковых эпох, содержат большое количество переотложенных пыльцы и спор, которые не позволяют делать верные стратиграфические выводы. Начались поиски возможностей разграничения разновозрастных палиноморф в спектрах. Наиболее эффективным оказался эколого-географический анализ, основанный на достаточно большом количестве видовых определений пыльцы и спор (Гричук и др., 1969). В результате этого довольно надежно разграничиваются инситные и переотложенные части спектров. На основе автохтонных пыльцы и спор производятся реконструкция палеорастительности и восстановление климатических условий. Переотложенные - аллохтонные палиноморфы, как мешающие, обычно не используются при исследованиях. По нашему мнению, такие пыльца и споры также носят ценную информацию. Конечно, они не могут дать сведений о палеоклимате и о характере растительности во время накопления вмещающих их отложений, так как они утратили ту классическую роль в палинологии, к которой мы привыкли. Подвергаясь переотложению они становятся неотъемлемой частью минерогенных отложений и носят такую же информацию как и минерогенные частицы. В результате их изучения можно установить пути и породы, по которым двигались ледники, а также отложения, которые разрушались и переотлагались. Возраст отложений ледниковых эпох обычно определяется по межледниковым слоям, последние, однако, редки. К тому же они редко находятся в коренном залегании. Поэтому существует острая необходимость в дополнительных критериях определения возраста отложений ледниковых эпох. По нашему мнению, одной такой возможностью является изучение переотложенной из межледниковых отложений пыльцы.

Из-за краткости четвертичного периода эволюционный принцип при различении межледниковий не применим. Отдельные реликтовые элементы и вымершие виды, используемые в этих целях (Гричук, 1961), редки и могут не встречаться в переотложенном состоянии. Сукцессии в растительности, представленные в виде пыльцевых зон, в процессе переотложения нарушаются. Так, почти все качественные критерии определения возраста спорово-пыльцевых спектров в процессе переотложения исчезают. Сохраняются лишь некоторые количественные критерии. Наиболее устойчивыми являются некоторые количественные соотношения пыльцы термофильных пород климатических оптимумов межледниковий. Так, на территории Прибалтики и прилегающих районов микулинские отложения очень богаты пыльцой ольхи и лещины. Лих- 


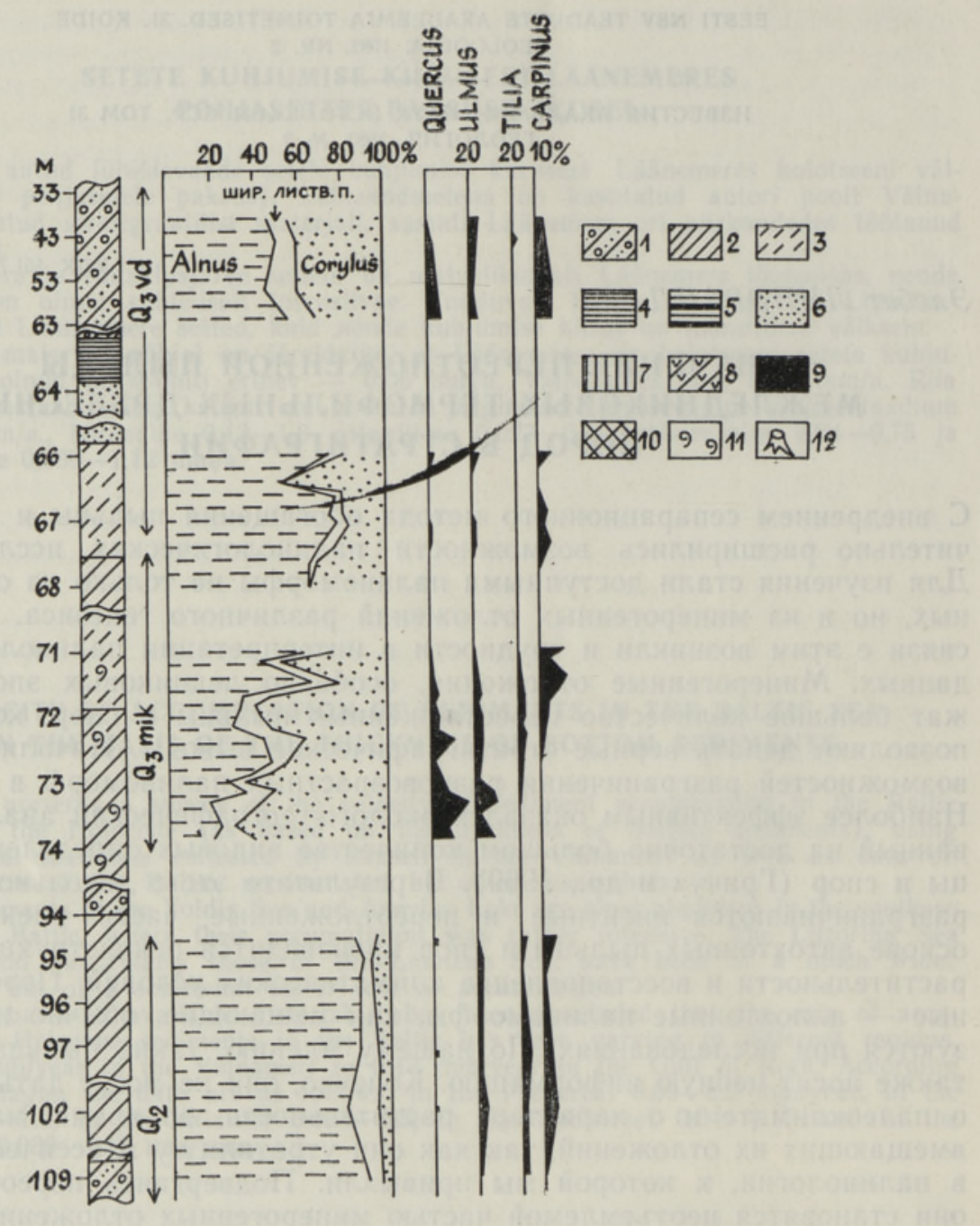

Рис. 1. Диаграмма пыльцы термофильных пород плейстоценовых отложений разреза Суур-Прангли. 1 - морена, 2 суглинок, 3 - супесь, 4 - глина, 5- ленточная глина, 6 - песок, 7 - древесный торф, 8 - тростниковый торф, 9 - торф, 10 - сапропелит, 11 - моллюски, 12 - остатки и стволы древесины.

винские отложения богаты только пыльцой ольхи, но бедны пыльцой лещины. Количество последней иногда даже меньше, чем ныльцы широколиственных пород. Такие закономерности ясно прослеживаются по всем пыльцевым диаграммам рассматриваемого района, а также по вариопраммам (Лийвранд, 1969, 1976). Однако прослеживанию количественных соотношений пыльцы отдельных термофильных пород во всех этих случаях является помехой наличие пыльцы других пород. Поэтому для большей наглядности последние исключены из диаграмм (рис. $1-4)$.

Известно, что микулинские слои являются одними из главных источников переотложения позднеплейстоценового оледенения, а лихвинские среднеплейстоценового оледенения. Следовательно, отложения этих ледниковий должны быть обогащены соответствующими комплексами переотложенной пыльцы термофилыных пород. Проверить такую 

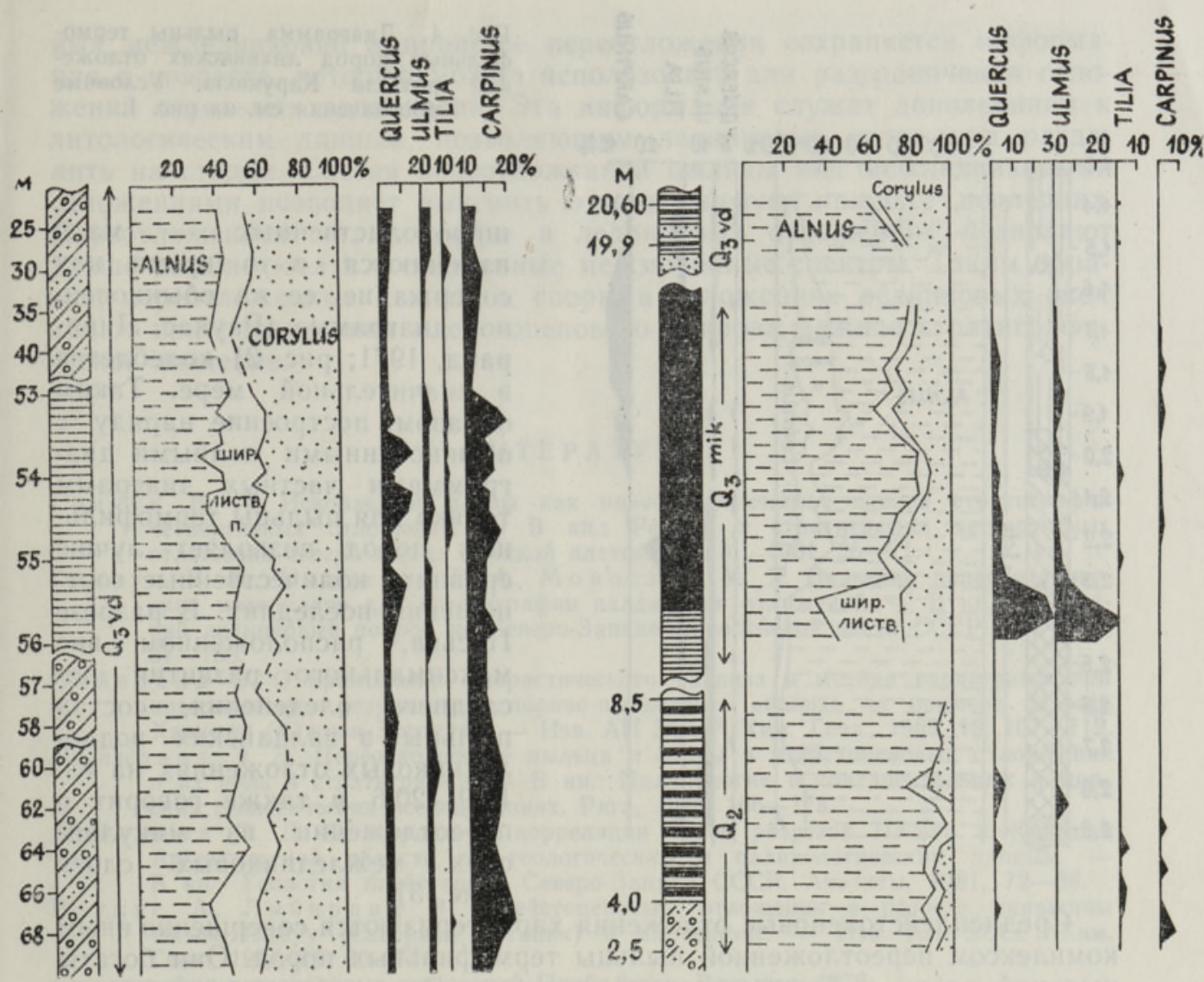

Рис. 2. Диаграмма пыльцы термофильных пород плейстоценовых отложений разреза Вяэна-Йээуу. Условные обозначения см. на рис. 1 .

Рис. 3. Диаграмма пыльцы термофнльных пород плейстоценовых отложений разреза Пасьва. Условные обозначения см. на рис. 1.

закономерность можно по опорным разрезам, где межледниковые отложения находятся, несомненно, в коренном залегании. Примерами могут служить разрез Суур-Прангли в предглинтовой части Эстонии (Стратиграфия четвертичных отложений Прибалтики, 1976) и разрез Пасьва на берегу долины р. Вага - левого притока Северной Двины (Лийвранд, 1981).

Микулинские отложения климатического оптимума на гл. $71,0-74,0 \mathrm{M}$ на о-ве Суур-Прангли (рис. 1) характеризуются большим количеством пыльцы лещины и ольхи, содержание которой по разрезу изменяется согласно сукцессиям растительности. Такая же закономерность наблюдается и в составе пыльцы широколиственных пород - дуба, вяза, липы, граба. Залегающие выше нижневалдайские слои $(66,0-67,5$ м) характеризуются наличием только переотложенной из верхней части микулинских слоев пылыцы. Валдайские морены на гл. $38,0-63,0$ м отличаются уже более осредненным составом переотложенной пыльцы из отложений всего климатического оптимума. Такой же состав пыльцы прослеживается в валдайских отложениях разреза Вяэна-Йэсуу (рис. 2), расположенного тоже в предглинтовой области в 44 км югозападнее о-ва Суур-Прангли. Такие спектры переотложенной пыльцы лишены закономерностей развития растительности. При этом количественные соотношения пыльцы термофильных пород - ольхи, лещины, 
Рис. 4. Диаграмма пыльцы термофильных пород лихвинских отложений разреза Карукюла, Условные обозначения см. на рис. 1 .

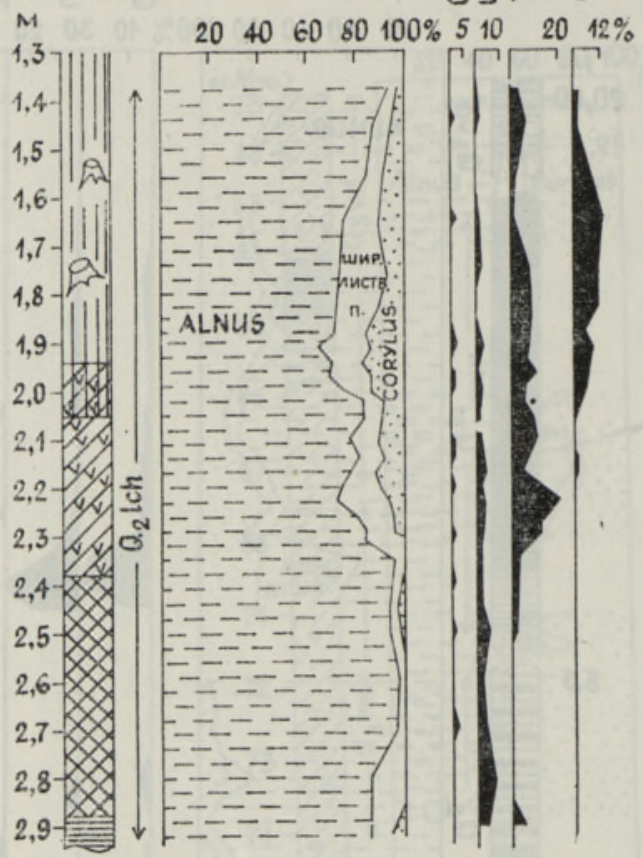

широколиственных - мало изменяются, в то время как содержание ее на обыкновенной диаграмме (Раукас, Лийвранд, 1971 ; рис. 2) колеблется в значительной мере. Таким образом, построение наряду с обыкновенными полными диаграммами частных диаграмм только для пыльцы термофильных пород позволяет лучше сравнить количественные соотношения последних. В разрезе Пасьва, расположенном вне максимального развития последнего оледенения, состав пыльцы в валдайских водноледниковых отложениях на гл. $19,9-20,6$ м также говорит о переотложении из микулинских межледниковых слоев (рис. 3).

Среднеплейстоценовые отложения характеризуются совершенно иным комплексом переотложенной пыльцы термофильных пород. Они богаты пыльцой ольхи и бедны пыльцой лещины. Это наблюдается как по разрезам Суур-Прангли (рис. 1, гл. 94,5-109,0 м), так и Пасьва (рис. 3, гл. 2,5-8,5 м). Такая закономерность обусловлена тем, что переотложение произошло из лихвинских межледниковых отложений, которые характеризуются соответствующими пыльцевыми спектрами. Это видно по Прибалтийским лихвинским разрезам (Стратиграфия..., 1976), в том числе и по разрезу Карукюла (рис. 4).

Подобные закономерности в распределении переотложенной пыльцы в отложениях ледниковых эпох, видимо, прослеживаются всюду. Но они могут нарушаться в случае перемешивания пыльцы различных межледниковий или же в случае размыва, например, лихвинских отложений во время валдайского оледенения. По-видимому, такие возможности все же редки. Отложения какого-то определенного межледниковья разрушаются главным образом уже во время последующего оледенения.

Определение возраста отложений ледниковых эпох с применением переотложенной пыльцы оправдано только из пород таких межледниковий, которые хорошо изучены и возраст которых бесспорный. Такими являются общепризнанные микулинское и лихвинское межледниковья. Однако при этом необходимо учитывать и некоторые региональные особенности развития растительности. На территории Прибалтики и прилегающих районов количество широколиственных пород увеличивается с севера на юг. В этом же направлении несколько увеличивается количество лещины, а ольхи, наоборот, уменьшается.

Находящимся почти всюду в ледниковых отложениях переотложенным пыльце и спорам не уделяется еще достаточного внимания. Все же в количественном составе пыльцы термофильных пород определен- 
ных межледниковий в процессе переотложения сохраняется информация о возрасте, которую можно использовать для разграничения отложений отдельных ледниковий. Эта информация служит дополнением к литологическим данным, позвөляющим ледниковые отложения разделить на стадии. Состав переотложенной пыльцы под межледниковыми отложениями позволяет выяснить отторженцевую природу последних. Переотложенные палиноморфы в ледниковых отложениях позволяют лучше расшифровать и смешанные межморенные спектры. Таким образом, переотложенные пыльца и споры в отложениях ледниковых эпох имеют при расчленении плейстоценового покрова важное стратиграфическое значение.

\section{Л И ТЕ Р А Т Р А}

Гричук В. П. Ископаемые флоры как палеонтологическая основа стратиграфин четвертичных отложений. - В кн.: Рельеф и стратиграфия четвертичных отложеннй северо-запада Русской платформы. М., 1961, 25-71.

Гричук В. П., Мальгин а Е. А., Моносзон М. Х. Значение палеоботанических материалов для стратиграфии валдайских отложений. - В кн.: Последний ледниковый покров на Северо-Западе Европейской части СССР. М., 1969, $57-105$.

Л и й в ранд Э. О примененин флористического анализа и метода вариограмм при интерпретащии результатов спорово-пыльщевого анализа на примере разреза Харимяэ (Южная Эстония). - Изв. АН ЭССР. Хим. Геол., 1969, 18, $107-112$.

Л и й в ра нд Э. Д. Переотложенные пыльца и споры в плейстоценовых отложениях и нх роль в стратиграфии. - В кн.: Палинология в континентальных и морских геологических исследованиях. Рига, 1976, 166-178.

Л и й в ра нд Э. Д. О возрасте и корреляции слоев разрезов Пасьва и Колешки Архангельской области по геологическим и палинологическим данным. В кн.: Геология плейстоцена Северо-Запада СССР. Апатиты, 1981, 72-86.

$\mathrm{P}$ а ука с А., Л и й в ранд Э. Плейстоценовые отложения в разрезе скважины Вяэна-Йесуу (Северная Эстония) и их генезис. - Изв. АН ЭССР. Хим. Геол., 1971, 20, 60-72.

Стратиграфия четвертичных отложений Прибалтики. Вильнюс, 1976.

Институт геологии

Академии наук Эстонской ССР
Поступила в редакцию

$8 /$ VII 1981

\section{Elsbet LIIVRAND}

\section{JÃAVAHEAEGSETE SOOJALEMBESTE PUUDE OMBERSETTINUD OIETOLMU TÄHTSUS STRATIGRAAFIAS}

Artiklis on tổestatud, et jäätumisaja setete vanuse määramiseks saab edukalt kasutada jäävaheaegsetest kihtidest ümbersettinud laialeheliste puude, lepa ja sarapuu õietolmu.

\section{Elsbet LIIVRAND}

\section{IMPORTANCE OF THE REBEDDED POLLEN OF INTERGLACIAL THERMOPHILIC TREES IN STRATIGRAPHY}

Because of the small number of interglacial deposits in the normal autochthonous bedding, the rebedded pollen of broad-leaved trees, alder and hazel, are suggested for use at the age determination of glacial and aqueoglacial deposits. A certain rebedded pollẹn composition has been noticed in Middle and Late Pleistocene deposits. 